\title{
Preliminary Evaluation of a New Index to Predict the Outcome of a Spontaneous Breathing Trial
}

\author{
Stéphane Delisle MSc, Martin Francoeur RRT, Martin Albert MD, Paul Ouellet RRT, \\ Patrick Bellemare MD, and Pierre Arsenault PhD
}

\begin{abstract}
BACKGROUND: The available predictors of spontaneous-breathing-trial (SBT) success/failure lack accuracy. We devised a new index, the CORE index (compliance, oxygenation, respiration, and effort). OBJECTIVE: To compare the CORE index to the CROP index (compliance, rate, oxygenation, and pressure), airway-occlusion pressure $0.1 \mathrm{~s}$ after the start of inspiratory flow $\left(\mathrm{P}_{0.1}\right)$, and rapid shallow breathing index (RSBI) for predicting SBT success/failure in a critical care environment. METHODS: With 47 mechanically ventilated patients recovering from respiratory failure, of various causes, we prospectively examined the SBT success/failure prediction accuracy and calculated receiver operating characteristic curves, sensitivity, specificity, and likelihood ratios of CORE, CROP, $P_{0.1}$, and RSBI. RESULTS: The specificities were CORE 0.95, $P_{0.1} 0.70$, CROP 0.70, and RSBI 0.65. The sensitivities were CORE 1.00, CROP 1.00, $P_{0.1} 0.93$, and RSBI 0.89. The areas under the receiver operating characteristic curve were CORE 1.00 (95\% CI 0.92-1.00), CROP 0.91 (95\% CI 0.79-0.97), $\mathrm{P}_{0.1} 0.81$ (95\% CI 0.67-0.91), and RSBI 0.77 (95\% CI 0.62-0.88). The positive likelihood ratios were CORE 20.0, CROP 3.3, $P_{0.1}$ 3.1, and RSBI 2.5. The negative likelihood ratios were CORE 0.0, CROP 0.0, $P_{0.1} 0.1$, and RSBI 0.2. CONCLUSIONS: The CORE index was the most accurate predictor of SBT success/failure. Key words: mechanical ventilation; spontaneous breathing trial; CROP index; $P_{0.1}$, rapid shallow breathing index. [Respir Care 2011;56(10):1500-1505. (C) 2011 Daedalus Enterprises]
\end{abstract}

\section{Introduction}

Mechanical ventilation is commonly used in the intensive care unit (ICU) to sustain lung function and protect the airways of critically ill patients. Determining which patients will tolerate removal of respiratory support and extubation is difficult. Unsuccessful weaning from mechanical ventilation often results in respiratory-muscle fatigue $^{1,2}$ and re-intubation. ${ }^{3,4}$ Unsuccessful extubation is as-

Mr Delisle is affiliated with the Respiratory Therapy Department, Hôpital du Sacré-Cœur, Montréal, Québec, Canada. Mr Francoeur is affiliated with the Respiratory Therapy Department, Hôpital Notre-Dame, Montréal, Québec, Canada. Drs Albert and Bellemare are affiliated with the Critical Care Division, Department of Medicine, Hôpital du Sacré-Cœur, Montréal, Québec, Canada. Mr Ouellet is affiliated with the Intensive Care Unit, Regional Health Authority Four, Edmundston, New Brunswick, Canada. Dr Arsenault is affiliated with the Centre de Recherches Cliniques du Centre Hospitalier Universitaire de Sherbrooke, Sherbrooke, Québec, Canada.

Supplementary material related to this paper is available at http://www. rcjournal.com. sociated with higher mortality, prolonged mechanical ventilation, longer ICU and hospital stay, and transfer to a long-term-care facility. ${ }^{5,6}$ Traditionally, discontinuation of mechanical ventilation and extubation were carried out

See the Related Editorial on Page 1621

after the attending clinician's evaluation, arterial blood gas analysis, and observation of the patient's clinical condi-

\footnotetext{
The authors have disclosed no conflicts of interest.

Mr Delisle presented a version of this paper at 34th Congress of the Société de Réanimation de Langue Française held January 18-20, 2006, in Paris, France.

Correspondence: Stéphane Delisle MSc, Respiratory Therapy Department, Hôpital du Sacré-Cœur, 5400 Boulevard Gouin Ouest, Montréal, Québec H4J 1C5 Canada. E-mail: sdelisle@ hotmail.com.
}

DOI: $10.4187 /$ respcare. 00768 
tion. ${ }^{7,8}$ This method requires clinical experience and it is nearly impossible to replicate the results and assess muscle fatigue. 7,8

Several predictors of successful termination of ventilatory support have been validated. ${ }^{9}$ In predicting a successful weaning, these predictors have good sensitivity but low specificity. ${ }^{9}$ Yang and Tobin ${ }^{10}$ proposed the CROP index:

$$
\mathrm{CROP}=\left[\mathrm{C}_{\mathrm{dyn}} \times \mathrm{P}_{\mathrm{Imax}} \times\left(\mathrm{P}_{\mathrm{aO}_{2}} / \mathrm{P}_{\mathrm{AO}_{2}}\right)\right] / \mathrm{f}
$$

in which $\mathrm{C}_{\mathrm{dyn}}$ is dynamic compliance, $\mathrm{P}_{\mathrm{Imax}}$ is maximum inspiratory pressure, $\mathrm{P}_{\mathrm{AO}_{2}}$ is alveolar partial pressure of oxygen, and $\mathrm{f}$ is respiratory rate. The CROP index has the same specificity as the individual predictors. ${ }^{10}$ Some studies have found a high specificity for the ratio of airwayocclusion pressure $0.1 \mathrm{~s}$ after the start of inspiratory flow $\left(\mathrm{P}_{0.1}\right)$ to $\mathrm{P}_{\text {Imax }}$ to predict a successful spontaneous breathing trial (SBT). ${ }^{3,11}$ We previously found $\mathrm{P}_{0.1}$ to be a valuable index of respiratory-center output, ${ }^{12}$ and it has a high enough sensitivity and specificity to contribute to better guidance of weaning from mechanical ventilation. ${ }^{13} \mathrm{We}$ devised the CORE index:

$$
\mathrm{CORE}=\left[\mathrm{C}_{\mathrm{dyn}} \times\left(\mathrm{P}_{\operatorname{Imax}} / \mathrm{P}_{0.1}\right) \times\left(\mathrm{P}_{\mathrm{aO}_{2}} / \mathrm{P}_{\mathrm{AO}_{2}}\right)\right] / \mathrm{f}
$$

The objective of this preliminary study was to compare the capacity of CORE, CROP, $\mathrm{P}_{0.1}$, and rapid shallow breathing index (RSBI) to predict SBT success/failure. We hypothesized that adding $\mathrm{P}_{0.1}$ to the CROP index would improve SBT success/failure prediction, which would decrease the number of failed SBTs and help screen patients earlier for SBT. We did not study the impact of CORE, CROP, $\mathrm{P}_{0.1}$, or RSBI on extubation success.

\section{Methods}

This study was approved by our institution's ethics committee, and we obtained written informed consent from each patient's surrogate.

\section{Patients}

We studied 47 adult patients recovering from respiratory failure, of various causes, in our academic mixed medical/surgical ICU at Hôpital du Sacré-Coeur, Montréal, Québec, Canada. All the patients were orotracheally intubated (7.0-8.0 mm inner diameter endotracheal tube), mechanically ventilated (Evita 2 or Evita 4, Dräger, Lübeck, Germany), and monitored with electrocardiography, radial artery indwelling catheter, and pulse oximetry. All the patients were on pressure support ventilation before study inclusion and data collection.
Patients were enrolled when the underlying cause of respiratory failure had improved and all the following inclusion criteria were met: $\mathrm{S}_{\mathrm{pO}_{2}} \geq 90 \%, \mathrm{P}_{\mathrm{aO}_{2}} \geq 60 \mathrm{~mm} \mathrm{Hg}, \mathrm{F}_{\mathrm{IO}_{2}} \leq 0.4$, PEEP $\leq 5 \mathrm{~cm} \mathrm{H}_{2} \mathrm{O}$, respiratory rate $\leq 35$ breaths/min, rectal temperature $<38^{\circ} \mathrm{C}$, hemoglobin $\geq 8 \mathrm{~g} / \mathrm{dL}$, no continuous intravenous sedation/analgesia (benzodiazepines, opioids, propofol, or barbiturates) for at least 48 hours, good patient cooperation, and no inotropes or vasopressors. We excluded patients with tracheotomy or hypertensive intracerebral hemorrhage. We calculated Acute Physiological and Chronic Health Evaluation (APACHE II) score for each patient. ${ }^{14}$

\section{Protocol}

Pressure support was initially set at $8 \mathrm{~cm} \mathrm{H}_{2} \mathrm{O}$ and PEEP at $4 \mathrm{~cm} \mathrm{H}_{2} \mathrm{O}$, for $30 \mathrm{~min}$, during which we continuously recorded vital signs. If the patient's vital signs were stable during those $30 \mathrm{~min}$, we measured the required respiratory variables and arterial blood gas values to calculate CORE, CROP, $\mathrm{P}_{0.1}$, and RSBI. The RSBI was calculated during the last minute without pressure support. Then the SBT was performed, with a T-piece and $\mathrm{F}_{\mathrm{IO}_{2}}$ of 0.4 , for $30 \mathrm{~min}$. At any time during the pressure support period or the T-piece trial, if vital signs deteriorated the patient was returned to their initial ventilation mode and the SBT was deemed a failure. Figure 1 depicts the procedure algorithm. The SBT was considered successful if all following criteria were met at the end of the $30 \mathrm{~min}$ : respiratory rate $\leq 35$ breaths $/ \mathrm{min}$, $\mathrm{P}_{\mathrm{aO}_{2}} \geq 60 \mathrm{~mm} \mathrm{Hg}, \mathrm{S}_{\mathrm{pO}_{2}} \geq 90 \%, \mathrm{P}_{\mathrm{aCO}_{2}}$ variation $\leq 5 \mathrm{~mm} \mathrm{Hg}$, heart rate increase $\leq 20$ beats/min, systolic blood pressure increase $\leq 30 \mathrm{~mm} \mathrm{Hg}$ or decrease $\leq 20 \mathrm{~mm} \mathrm{Hg}$, and diastolic blood pressure variation $\leq 20 \mathrm{~mm} \mathrm{Hg}$. All data analysis was performed afterward so that the attending physicians were blinded to the weaning predictors, and the decision for extubation was based solely on the physician's evaluation.

We obtained $\mathrm{P}_{0.1}$ from the ventilator. Following a passive expiration, the inspiratory valve closes and a transducer measures the airway pressure during the first $0.1 \mathrm{~s}$ following a patient effort; this is referred as $\mathrm{P} 1 .^{15}$ The $0.1 \mathrm{~s}$ time interval starts when a negative pressure of $-0.5 \mathrm{~cm} \mathrm{H}_{2} \mathrm{O}$ is measured as a result of the inspiratory effort. A second pressure reading (P2) is taken after $0.1 \mathrm{~s}$. Simultaneously, the inspiratory valve opens to resume breathing. The occlusion pressure after $0.1 \mathrm{~s}\left(\mathrm{P}_{0.1}\right)$ is defined as the difference between $\mathrm{P} 2$ and $\mathrm{P} 1$. The mean $\mathrm{P}_{0.1}$ is calculated from 3 consecutive measurements.

Maximum inspiratory pressure was defined as the most negative pressure recorded during 20 seconds of airway occlusion. ${ }^{16} \mathrm{C}_{\text {dyn }}$ was calculated as the expired tidal volume $\left(\mathrm{V}_{\mathrm{T}}\right)$ divided by the peak airway pressure minus PEEP. ${ }^{17}$ Maximum inspiratory pressure was measured with 


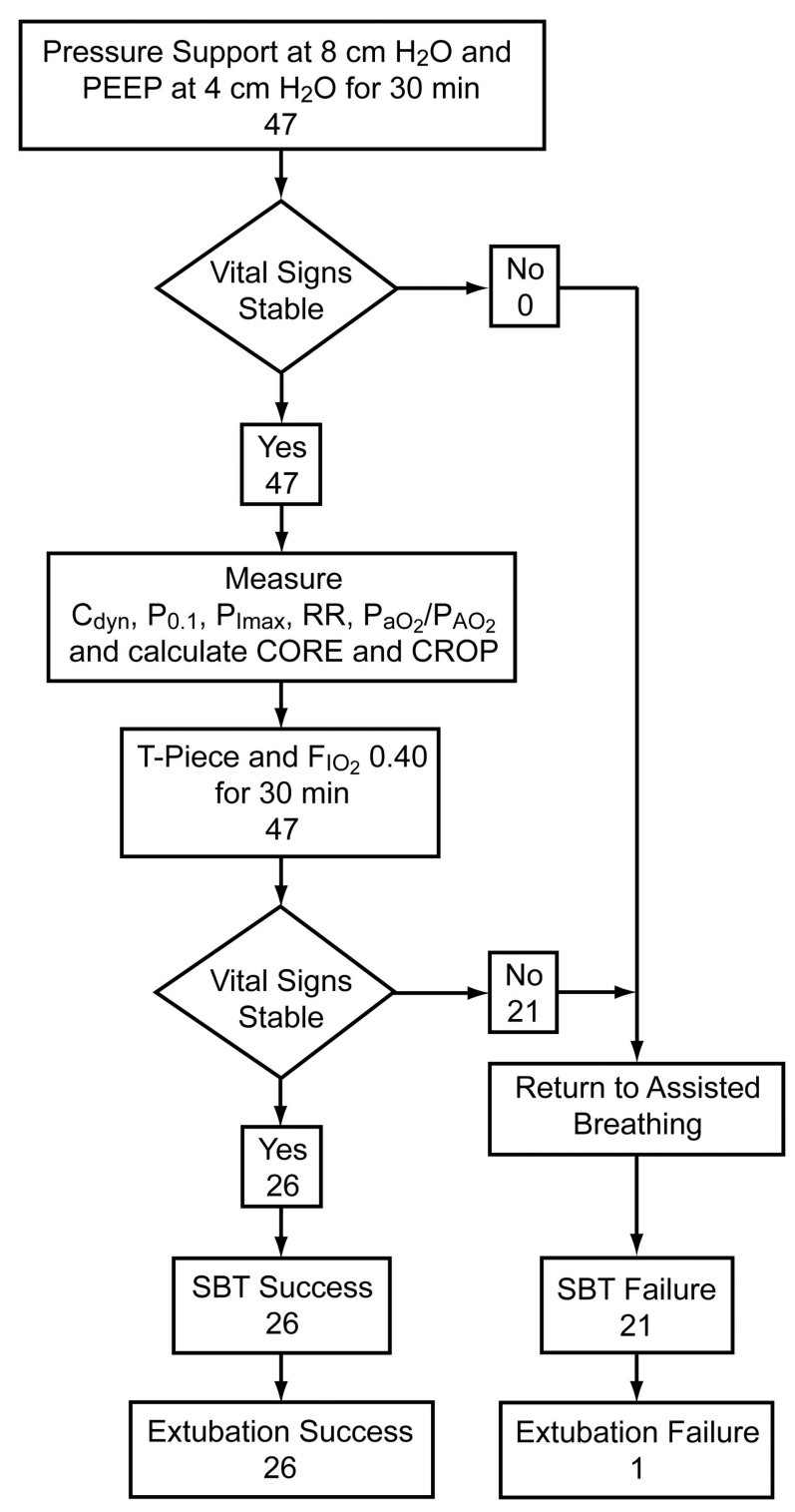

Fig. 1. Flow chart of pressure support test and spontaneous breathing trial (SBT). The rapid shallow breathing index (RSBI) was calculated on PEEP of $4 \mathrm{~cm} \mathrm{H}_{2} \mathrm{O}$ and without pressure support, over one minute, after the initial $30 \mathrm{~min}$ with pressure support of $8 \mathrm{~cm} \mathrm{H}_{2} \mathrm{O}$. The extubation decision was solely with the physician, who did not know the result of the calculated indexes. The physicians decided to extubate the 26 patients who successfully completed the SBT, and also one of the 21 patients who failed the SBT. That patient failed extubation due to acute respiratory distress, hypoxemia, and hypercapnia. $\mathrm{C}_{\mathrm{dyn}}=$ dynamic compliance. $\mathrm{P}_{\text {Imax }}=$ maximum inspiratory pressure. $\mathrm{f}=$ respiratory rate. $\mathrm{P}_{\mathrm{AO}_{2}}=$ alveolar partial pressure of oxygen.

a calibrated differential pressure transducer (S\&M Instruments, Doylestown, PA) and a unidirectional valve that allows expiration but not inspiration. RSBI was calculated following a continuous positive airway pressure of $4 \mathrm{~cm} \mathrm{H}_{2} \mathrm{O}$ and without pressure support, for one minute at the end of that 30 min. ${ }^{18}$ Minute ventilation and respira- tory rate were measured by the ventilator. $\mathrm{V}_{\mathrm{T}}$ was obtained by dividing the minute ventilation by the respiratory rate. An arterial blood gas sample was taken while the patient was on mechanical ventilation and oxygenation status was assessed with $\mathrm{P}_{\mathrm{aO}_{2}} / \mathrm{P}_{\mathrm{AO}_{2}} \cdot{ }^{19-23}$

\section{Statistical Analysis}

Values are presented as mean \pm SD unless otherwise specified. For variables that had a statistically significant difference between the 2 groups, the predictive performance of the chosen variable was evaluated by calculating the area under the receiver operating characteristic curve (AUC), calculated with MedCalc 8.0 (2005 Frank Schoonjans, Belgium). ${ }^{24}$

To construct receiver operating characteristic curves for each variable, we varied the threshold values for predicting SBT outcome and plotted the relationship between the calculated true positive and false-positive values for each cut-off point. The AUC provides an independent discriminator at the selected threshold value. ${ }^{25,26}$ For each variable the threshold values we used were those that resulted in the lowest false-positive and false-negative values. The comparison of the AUC values and $95 \%$ confidence intervals was via a non-parametric Wilcoxon approach. ${ }^{27} P<.05$ was considered significant. According to one arbitrary guideline, ${ }^{28}$ a non-informative predictor has an AUC of $<0.5$, a low-accuracy predictor has an AUC of 0.5-0.7, a moderately accurate predictor has an AUC of $>0.7-0.9$, and highly accurate predictor has an AUC of $>0.9$. Perfect prediction accuracy is an AUC of 1.28

\section{Results}

Table 1 describes the 47 subjects. There were 4 patients with COPD among the 12 acute-respiratory-failure patients. The mean age was $57.2 \pm 18.5$ years (range $22-83$ y). The mean APACHE II score was $15.4 \pm 4.2$. The APACHE II score was not associated with the weaning variables or SBT outcomes. The mean days on mechanical ventilation before inclusion was $5.6 \pm 6.1$ days (range 2-18 d).

Twenty patients (43\%) did not tolerate SBT (Table 2) and none of those patients could be liberated from mechanical ventilation within 48 hours. Thirteen patients had more than one reason for SBT failure. Patients who failed SBT were mechanically ventilated for longer than those who successfully completed the SBT $(9.0 \pm 2.6 \mathrm{~d}$ vs $7.1 \pm 2.8 \mathrm{~d}, P=.03)$.

Twenty-six patients $(55 \%)$ were successfully liberated from mechanical ventilation after the $30 \mathrm{~min}$ T-piece SBT, but one patient required re-intubation and mechanical ventilation within 48 hours. Individual data of the indexes and $\mathrm{T}$-piece outcomes are available in the supplementary material at http://rcjournal.com. 
Table 1. Subjects $(n=47)$

\begin{tabular}{|c|c|}
\hline Age (mean \pm SD y) & $57.2 \pm 18.5$ \\
\hline Male, no. & 26 \\
\hline Female, no. & 21 \\
\hline APACHE II (mean \pm SD score) & $15.4 \pm 4.2$ \\
\hline \multicolumn{2}{|l|}{ Mechanical Ventilation Days, no. } \\
\hline $2-3$ & 5 \\
\hline $3-4$ & 8 \\
\hline $5-6$ & 14 \\
\hline$>7$ & 20 \\
\hline \multicolumn{2}{|l|}{ Indication for Intubation, no. } \\
\hline Trauma & 12 \\
\hline Acute respiratory failure & 12 \\
\hline Congestive heart failure & 11 \\
\hline Neurological disorder & 4 \\
\hline Others & 8 \\
\hline \multicolumn{2}{|l|}{$\overline{\mathrm{APACHE}}=$ Acute Physiology and Chronic Health Evaluation } \\
\hline \multicolumn{2}{|c|}{ Table 2. Reasons for Spontaneous Breathing Trial Failure } \\
\hline Reason & No. \\
\hline Tachypnea ( $>35$ breaths/min) & 9 \\
\hline $\begin{array}{l}\text { Hypertension (increase of }>30 \mathrm{~mm} \mathrm{Hg} \text { systolic or } \\
10 \mathrm{~mm} \mathrm{Hg} \text { diastolic) }\end{array}$ & 9 \\
\hline Hypercapnia $\left(\mathrm{P}_{\mathrm{aCO}_{2}}\right.$ increase of $\left.>5 \mathrm{~mm} \mathrm{Hg}\right)$ & 7 \\
\hline Tachycardia (heart rate increase of $>20$ beats $/ \mathrm{min}$ ) & 4 \\
\hline Hypoxemia $\left(\mathrm{P}_{\mathrm{aO}_{2}}<60 \mathrm{~mm} \mathrm{Hg}\right)$ & 2 \\
\hline
\end{tabular}

We determined the threshold value for each variable with the receiver operating characteristic curve (Fig. 2). Table 3 shows the threshold values, sensitivities, specificities, positive predictive values, negative predictive values, and AUCs. The specificity was highest for CORE (0.95), and the positive likelihood ratio was highest for CORE (20.0). The $P$ values for the AUC comparisons are: $P=.001$ for CORE versus RSBI, $P=.003$ for CORE versus $\mathrm{P}_{0.1}$, $P=0.03$ for CORE versus CROP, and $P=.64$ for $\mathrm{P}_{0.1}$ versus RSBI. All the AUCs were significantly greater than an arbitrary test that has no discriminatory value (ie, AUC $<0.5$ ).

\section{Discussion}

The CORE index was the most powerful SBT predictor, with an AUC of 1.00 (95\% CI 0.92-1.00) and had the highest sensitivity and specificity. A major difficulty for predictors of SBT is their low specificity. A low specificity favors false-positive results, which can lead to premature SBT, which could cause harmful muscle fatigue. ${ }^{3,4}$ Unsuccessful extubation is associated with higher mortality, prolonged mechanical ventilation, longer ICU and hospital stay, and transfer to a long-term-care facility. $.5,6$
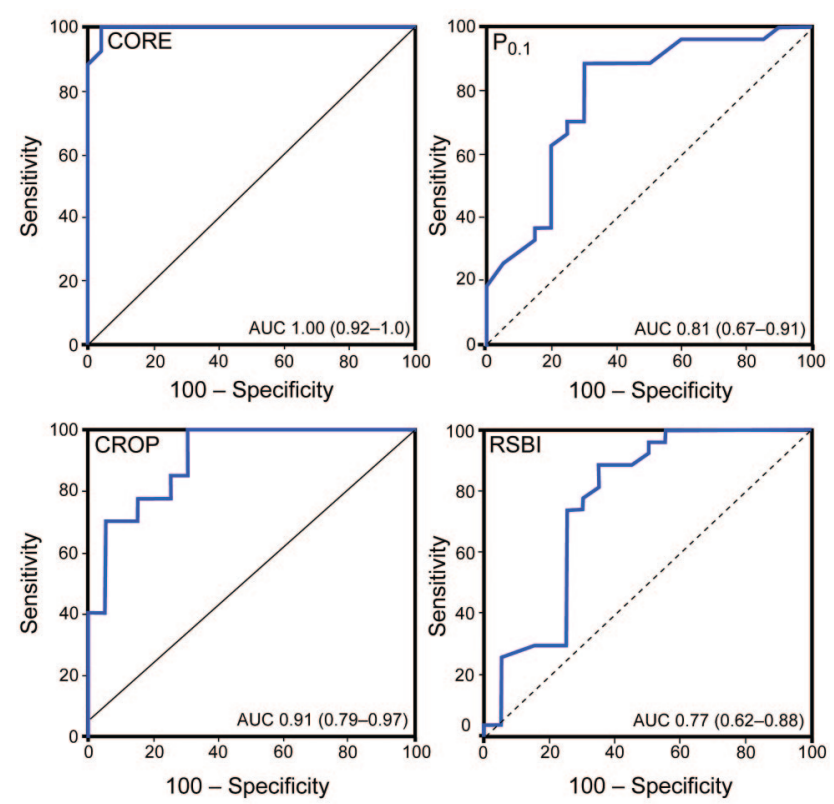

Fig. 2. Receiver operating characteristic curves for the CORE (compliance, oxygenation, respiration, and effort), the CROP index (compliance, rate, oxygenation, and pressure), airway-occlusion pressure $0.1 \mathrm{~s}$ after the start of inspiratory flow $\left(\mathrm{P}_{0.1}\right)$, and rapid shallow breathing index (RSBI). The threshold values that provided the fewest false positives and false negatives were: CORE $>8$, $\mathrm{CROP}>25.2, \mathrm{P}_{0.1} \leq 3.8 \mathrm{~cm} \mathrm{H} \mathrm{H}_{2} \mathrm{O} \mathrm{RSBI} \leq 69$ breaths $/ \mathrm{min} / \mathrm{L}$. The area-under-the-curve values are shown with their $95 \% \mathrm{Cls.}$

RSBI is the most commonly used predictor of weaning outcome. However, RSBI has low accuracy for predicting SBT outcome. ${ }^{9}$ Comparable to what we found in the present study, the average reported sensitivity and specificity of RSBI are reported to be $0.87 \pm 0.14$ and $0.52 \pm 0.26$, respectively. ${ }^{29}$ During the SBT the RSBI was also found to stay within the normal range even though the repeated measurements in the esophageal pressure swings showed an increase in respiratory effort and weaning failure. ${ }^{30} \mathrm{In}$ a recent study, ${ }^{31}$ the use of the RSBI did not improve weaning outcome, and it delayed weaning for 2-3 days. Muscle fatigue during an SBT is a complex process that obviously cannot be well predicted based solely on respiratory rate and $\mathrm{V}_{\mathrm{T}}$.

We incorporated $\mathrm{P}_{0.1}$ in the CORE index for several reasons. $\mathrm{P}_{0.1}$ reliably reflects respiratory-center output and is not influenced by the patient's airway resistance or lung compliance. ${ }^{12}$ In patients with acute respiratory failure, $\mathrm{P}_{0.1}$ has a specificity of 1.00 and a sensitivity of 0.78 with a threshold $4.2 \mathrm{~cm} \mathrm{H}_{2} \mathrm{O} .{ }^{13} \mathrm{P}_{0.1}$ also correlates with work of breathing ${ }^{32}$ and with the adjustment of the pressure support level..$^{33} \mathrm{We}$ therefore feel that $\mathrm{P}_{0.1}$ is very informative and reliable in the weaning process.

The CROP index was found to be a better predictor than RSBI in a pediatric study, ${ }^{34}$ but CROP is less often used than RSBI, mainly because of CROP's complexity. The 
A New Index to Predict the Outcome of a Spontaneous Breathing Trial

Table 3. Accuracy of 4 SBT Prediction Indexes

\begin{tabular}{|c|c|c|c|c|c|c|c|c|}
\hline \multirow{2}{*}{ Index } & \multirow{2}{*}{ Threshold } & \multirow{2}{*}{$\begin{array}{l}\text { Sensitivity } \\
\text { (CI 95\%) }\end{array}$} & \multirow{2}{*}{$\begin{array}{l}\text { Specificity } \\
\text { (CI 95\%) }\end{array}$} & \multirow{2}{*}{$\begin{array}{l}\text { Positive } \\
\text { Predictive } \\
\text { Value }\end{array}$} & \multirow{2}{*}{$\begin{array}{c}\text { Negative } \\
\text { Predictive } \\
\text { Value }\end{array}$} & \multirow{2}{*}{$\begin{array}{l}\text { Area Under the } \\
\text { Curve (CI 95\%) }\end{array}$} & \multicolumn{2}{|c|}{ Likelihood Ratio } \\
\hline & & & & & & & Positive & Negative \\
\hline CORE & $>8$ & $1.00(0.87-1.00)$ & $0.95(0.75-0.99)$ & 0.96 & 1.00 & $1.00(0.92-1.00)$ & 20.0 & 0.0 \\
\hline CROP & $>25.2$ & $1.00(0.87-1.00)$ & $0.70(0.46-0.88)$ & 0.82 & 1.00 & $0.91(0.79-0.97)$ & 3.3 & 0.0 \\
\hline $\mathrm{P}_{0.1}$ & $\leq 3.8$ & $0.93(0.76-0.99)$ & $0.70(0.46-0.88)$ & 0.81 & 0.88 & $0.81(0.67-0.91)$ & 3.1 & 0.1 \\
\hline RSBI & $\leq 69$ & $0.89(0.71-0.98)$ & $0.65(0.41-0.85)$ & 0.77 & 0.81 & $0.77(0.62-0.88)$ & 2.5 & 0.2 \\
\hline \multicolumn{9}{|c|}{$\begin{array}{l}\text { SBT }=\text { spontaneous breathing trial } \\
\text { CORE = compliance, oxygenation, respiration, and effort index } \\
\text { CROP = compliance, rate, oxygenation, and pressure index } \\
\mathrm{P}_{0.1}=\text { airway-occlusion pressure } 0.1 \mathrm{~s} \text { after the start of inspiratory flow } \\
\mathrm{RSBI}=\text { rapid shallow breathing index }\end{array}$} \\
\hline
\end{tabular}

CORE index expresses the respiratory effort with the $\mathrm{P}_{\text {Imax }} /$ $\mathrm{P}_{0.1}$ ratio, whereas the CROP index expresses it only with $\mathrm{P}_{\mathrm{Imax}}$. By further analyzing the results of the CORE index, we found that when using only $\mathrm{P}_{0.1}$ we had to use the $1 / \mathrm{P}_{0.1}$ ratio to express a variable positively related to $\mathrm{C}_{\mathrm{dyn}}$ and $\mathrm{P}_{\mathrm{aO}} / \mathrm{P}_{\mathrm{AO}_{2}}$. When using only the $1 / \mathrm{P}_{0.1}$ variable, without association with $\mathrm{P}_{\text {Imax }}$, we obtained a specificity of 0.90, which is better than the specificity of the CROP index (0.70) and worse than that of the CORE index (0.95).

We feel this association demonstrates that the validity of the CORE index is not a matter of coincidence but truly reflects a strong predictive outcome assessment of the patient's neuromuscular ability to support spontaneous breathing without assistance. In fact, the CORE index had approximately 6 times more predictive power than $\mathrm{P}_{0.1}$, CROP, or RSBI in the patients who tolerated SBT. Based on $\mathrm{P}_{0.1}$, CROP, and RSBI, $13-15 \%$ of the patients in this study would not have been eligible for SBT but did successfully complete the SBT. On the other hand, based on the CORE index, only $2 \%$ of the patients would not have been eligible for SBT but did successfully complete the SBT.

The strengths of this study include that the attending physicians were blinded to the results and their patient evaluations were based solely on their judgment. The patients we studied were representative of the usual population in our medical/surgical and trauma ICU and in many similar tertiary-care centers. We believe that in the weaning process we must look at more variables than $\mathrm{V}_{\mathrm{T}}$ and respiratory rate-variables such as amount of secretions, patient cooperation, and the level of support during the SBT - to accurately predict SBT outcome and thus to facilitate and objectively standardize the weaning process.

We specifically examined SBT success/failure, but did not study extubation as an outcome. Whether the CORE index accurately predicts extubation success/failure also remains to be determined.

\section{Limitations}

Though the statistical analysis showed highly significant differences, this study included only 47 patients, similar to other weaning studies, ${ }^{4,34-36}$ and our results need validation in a prospective multicenter study. Our screening criteria were conservative in order to tightly control the protocol and therefore allow a better comparison of the 4 SBT predictors. However, our results might have been different with more liberal screening criteria. We focused on short-term (48 h) SBT outcome. Future studies of the CORE index should evaluate longer-term outcomes for SBT and extubation. Also, calculating the CORE index requires measurements that may limit its use in daily practice, though those measurements are already available in some ICUs. It may be possible to gather those data from a mechanical ventilator and advise the clinician about the patient's weaning status.

\section{Conclusions}

The CORE index was the most accurate predictor of SBT success/failure. If a future study confirms our results, the CORE index may help clinicians screen more patients faster and earlier in the weaning process and avoid inappropriate SBTs. Further studies are required to evaluate the CORE index in the ICU.

\section{REFERENCES}

1. Laghi F, D'Alfonso N, Tobin MJ. Pattern of recovery from diaphragmatic fatigue over 24 hours. J Appl Physiol 1995;79(2):539-546.

2. Reid WD, Huang J, Bryson S, Walker DC, Belcastro AN. Diaphragm injury and myofibrillar structure inducted by resistive loading. J Appl Physiol 1994;76(1):176-184.

3. Capdevila XJ, Perrigault PF, Ramonatxo M, Roustan JP, Peray P, d'Athis F, Prefaut C. Changes in breathing pattern and respiratory muscle performance parameters during difficult weaning. Crit Care Med 1998;26(1):79-87. 


\section{A New Index to Predict the Outcome of a Spontaneous Breathing Trial}

4. Vassilakopoulos T, Zakinthinos S, Roussos C. The tension-time index and the frequency/tidal volume ratio are the major pathophysiologic determinants of weaning failure and success. Am J Respir Crit Care Med 1998;158(2):378-385.

5. Epstein SK, Ciubotaru RL, Wong JB. Effect of failed extubation on the outcome of mechanical ventilation. Chest 1997;112(1):186-192.

6. Esteban A, Alía I, Gordo F, Fernández R, Solsona JF, Vallverdú I, et al. Extubation outcome after spontaneous breathing trials with t-tube or pressure support ventilation. Am J Respir Crit Care Med 1997; 156(2):459-465. Erratum in: Am J Respir Crit Care Med 1997;156(6): 2028.

7. Sahn SA, Lakshminurayan S. Bedside criteria for discontinuation of mechanical ventilation. Chest 1973;63(6):1002-1005.

8. Mador MJ. Weaning parameters: are they clinically useful? Chest 1992;102(6):1642-1643.

9. Meade M, Guyatt G, Cook D, Griffith L, Sinuff T, Kergl C, et al. Predicting success in weaning from mechanical ventilation. Chest 2001;120(6 Suppl):400S-424S.

10. Yang KL, Tobin MJ. A prospective study of indexes predicting the outcome of trials of weaning from mechanical ventilation. $\mathrm{N}$ Engl J Med 1991;324(21):1445-1450.

11. Gandia F, Blanco J. Evaluation of indexes predicting the outcome of ventilator weaning and value of adding supplemental inspiratory load. Intensive Care Med 1992;18(6):327-333.

12. Whitelaw WA, Derenne JP, Milic-Emili J. Occlusion pressure as a measure of respiratory center output in conscious man. Respir Physiol 1975;23(2):181-199.

13. Herrera M, Blasco J, Venegas J, Barba R, Doblas A, Marquez E. Mouth occlusion pressure (P0.1) in acute respiratory failure. Intensive Care Med 1985;11(3):134-139.

14. Knaus WA, Draper EA, Wagner DP, Zimmerman JE. APACHE II: a severity of disease classification system. Crit Care Med 1985; 13(10):818-829.

15. Kuhlen R, Hausmann S, Pappert D, Salma K, Rossaint R, Falke K. A new method for P0.1 measurement using standard respiratory equipment. Intensive Care Med 1995;21(7):554-560.

16. Marini JJ, Smith TC, Lamb V. Estimation of inspiratory muscle strength in mechanically ventilated patients: the measurement of maximal inspiratory pressure. J Crit Care 1986;1(1):32-38.

17. Tobin MJ. Respiratory monitoring in the intensive care unit. Am Rev Respir Dis 1988;138(6):1625-1642.

18. Ely EW, Baker AM, Dunagan DP, Burke HL, Smith AC, Kelly PT, et al. Effect on the duration of mechanical ventilation of identifying patients capable of breathing spontaneously. N Engl J Med 1996; 335(25):1864-1869.

19. Gilbert R, Keighley JF. The arterial/alveolar oxygen tension ratio: an index of gas exchange applicable to varying inspired oxygen concentrations. Am Rev Respir Dis 1974;109(1):142-145.
20. Biggerstaff BJ. Comparing diagnostic tests: a simple graphic using likelihood ratios. Stat Med 2000;19(5):649-663.

21. Jaeschke R, Guyatt GH, Sackett DL. Users' guides to the medical literature: how to use an article about a diagnostic test; are the results of the study valid? JAMA 1994;271(5):389-391.

22. Jaeschke R, Guyatt GH, Sackett DL. Users' guides to the medical literature: what are the results and will they help me in caring for my patients? JAMA 1994;271(9):703-707.

23. Irwig L, Tosteson AN, Gatsonis C, Lau J, Colditz G, Chalmers TC, Mosteller F. Guidelines for meta-analyses evaluating diagnostic tests. Ann Intern Med 1994;120(8):667-676.

24. ROC curve analysis in MedCalc. MedCalc, 2005. http://www.medcalc.org/manual/roc-curves.php. Accessed August 5, 2011.

25. Centor RM. Signal detectability: the use of ROC curves and their analyses. Med Decis Making 1991;11(2):102-106.

26. Daurès JP. [Use of ROC curves in medical imaging]. J Radiol 1991; 72(8-9):445-461. Article in French

27. Hanley JA, McNeil BJ. A Method of comparing the areas under receiver operating characteristic curves derived from the same cases. Radiology 1983;148(3):839-843.

28. Swets JA. Measuring the accuracy of diagnostic systems. Science 1988;240(4857):1285-1293.

29. Tobin MJ, Jubran A. Variable performance of weaning predictor tests: role of Bayes's theorem and spectrum and test referral bias. Intensive Care Med 2006;32(12):2002-2012.

30. Jubran A, Grant BJ, Laghi F, Parthasarathy S, Tobin MJ. Weaning prediction: esophageal pressure monitoring complements readiness testing. Am J Respir Crit Care Med 2005;171(11):1252-1259.

31. Tanios MA, Nevins ML, Hendra KP, Cardinal P, Allan JE, Naumova EN, Epstein SK. A randomized controlled trial of the role of weaning predictors in clinical decision making. Crit Care Med 2006;34(10): 2530-2535

32. Marini JJ, Rodriguez M, Lamb V. The inspiratory workload of patient-initiated mechanical ventilation. Am Rev Respir Dis 1986; 134(5):902-909.

33. Alberti A, Gallo F, Fongaro A, Valenti S, Rossi A. P0.1 is a useful parameter in setting the level of pressure support ventilation. Intensive Care Med 1995;21(7):547-553.

34. Baumeister BL, El-Khatib M, Smith PG, Blumer JL. Evaluation of predictors of weaning from mechanical ventilation in pediatric patients. Pediatr Pulmonol 1997;24(5):344-352.

35. Sassoon CS, Mahutte CK. Airway occlusion pressure and breathing pattern as predictors of weaning outcome. Am Rev Respir Dis 1993; 148(4 Pt 1):860-866.

36. Yang KL. Inspiratory pressure/maximal inspiratory pressure ratio: a predictive index of weaning outcome. Intensive Care Med 1993; 19(4):204-208

This article is approved for Continuing Respiratory Care Education credit. For information and to obtain your CRCE

(free to AARC members) visit

www.RCJournal.com

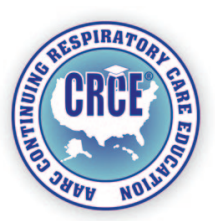

